\title{
Gastric cancer review
}

\author{
Lauren Peirce Carcas* \\ Department of Hematology and Oncology Sylvester Comprehensive Cancer Center, Miami, Florida 33136, USA \\ E-mail: laurencarcasmd@gmail.com \\ *Corresponding author \\ Published: 19 December, 2014 \\ Journal of Carcinogenesis 2014,13:14 \\ This article is available from: http://www.carcinogenesis.com/content//3/I/14 \\ () 2014 Carcas
}

Received: 17 July, 2014

Accepted: 14 October, 2014

\begin{abstract}
Gastric cancer is an aggressive disease that continues to have a daunting impact on global health. Despite an overall decline in incidence over the last several decades, gastric cancer remains the fourth most common type of cancer and is the second leading cause of cancer-related death worldwide. This review aims to discuss the global distribution of the disease and the trend of decreasing incidence of disease, delineate the different pathologic subtypes and their immunohistochemical (IHC) staining patterns and molecular signatures and mutations, explore the role of the pathogen $H$. pylori in tumorgenesis, discuss the increasing incidence of the disease in the young, western populations and define the role of biologic agents in the treatment of the disease.
\end{abstract}

Keywords: Biologic targeted therapy, diffuse subtype, gastric cancer, Helicobacter pylori, intestinal subtype

\section{INTRODUCTION}

Gastric cancer is an aggressive disease that continues to have a daunting impact on global health. Despite an overall decline in incidence over the last several decades, gastric cancer remains the fourth most common type of cancer and is the second leading cause of cancer-related death worldwide.$^{[1,2]}$ Although the incidence is declining due to improved nutrition, food preservation, better prevention, earlier diagnosis and treatment, the disease still carries a poor prognosis. Gastric cancer is often diagnosed at an advanced stage. The cornerstone of therapy is surgical resection with adjuvant chemotherapy or chemoradiation in appropriate cases. Such an approach has led to improved survival. ${ }^{[3,4]}$ Unfortunately, treatment of advanced or metastatic gastric cancer has seen

\begin{tabular}{|l|l|}
\hline \multicolumn{2}{|c|}{ Access this article online } \\
\hline Quick Response Code: & Website: \\
& www.carcinogenesis.com \\
\cline { 2 - 3 } & \\
\hline
\end{tabular}

little progress and median overall survival (OS) in this group remains $<1$ year. ${ }^{[5]}$ Gastric cancer is a heterogeneous disease that demands continued attention and research with regard to prevention, early detection and novel therapeutic options.

The global distribution of gastric cancer varies substantially across geographical regions which illustrate the multitude of factors that are associated with the incidence, survival and mortality of the disease. The Asian countries account for the majority of the world's cases while Europe and the Americas combined makeup less than a quarter of the world disease burden. ${ }^{[6,7]}$ Even within the highly affected areas, certain populations are more commonly afflicted; particularly the lower socioeconomic classes, and within the United States, the African American population. ${ }^{[6,8]}$

The two main histologic subtypes of the disease, intestinal and diffuse type, as classified by Lauren, ${ }^{[9]}$ define two distinct entities that have different epidemiology, etiology, pathogenesis and behavior. The last several decades have demonstrated a gradual decline in the rates of gastric cancer in most populations and across subtypes. Perhaps, the decline can be attributed in part to improved food preservation with 
the advent of electric refrigeration, ${ }^{[10]}$ increased accessibility to fresh fruits and vegetables year round, lower salt diets (less salt preservation), the decreased use of tobacco ${ }^{[11]}$ and eradication of Helicobacter pylori infections in endemic areas. However, whereas most gastric tumors are declining in incidence, tumors of the gastric cardia and gastroesophageal junction are becoming more frequent and there is a trend of rising incidence of noncardia gastric cancer among American whites between 25 and 39 years of age ${ }^{[12]}$ and in the same age group in other western countries. ${ }^{[13,14]}$

Environmental and nutritional factors have been implicated in the development of the disease. Consumption of salt and salt-preserved food, nitrates, and smoked or pickled foods have been associated with increased risk of developing gastric cancer. ${ }^{[10]}$ Much of the evidence about salt and food preservation, however, is indirect and is based on time trend comparisons. ${ }^{[10]}$ While tumors of the cardia and the gastroesophageal junction may be related to gastroesophageal reflux, a clear causal relationship exists between noncardia gastric cancers and chronic mucosal infection by the Class I human carcinogen, H. pylori. ${ }^{[15]}$ This review aims to discuss the global distribution of the disease and the trend of decreasing incidence of disease, delineate the different pathologic subtypes and their immunohistochemical (IHC) staining patterns and molecular signatures and mutations, explore the role of the pathogen H. pylori in tumorgenesis, discuss the increasing incidence of the disease in the young, western populations and define the role of biologic agents in the treatment of the disease.

\section{GLOBAL IMPACT}

Seventy-three percent of gastric cancer cases are diagnosed in Asia; almost $50 \%$ of the world's cases are diagnosed in China alone. ${ }^{[6,7]}$ Europe accounts for an additional 15\% and Central and South America contribute $7 \%$ of the global burden. ${ }^{[6,16]}$ Within these global regions, there is further variability as to which populations are more greatly affected. The incidence rate in men is double that of women and incidence increases with age. Even within the same geographic region certain ethnic groups have significantly higher risk of disease. Within the United States, Hispanics, African Americans, and Native Americans are more frequently affected than Caucasian Americans. ${ }^{[6,11]}$ However, ethnic predisposition cannot be considered alone since socioeconomic status also impacts disease incidence.

The incidence of gastric cancer can be further divided according to its location within the stomach with a distinction between the distal portion of the stomach (noncardia) and cancers arising from the proximal cardia region. ${ }^{[17]}$ The distinction for cardia versus noncardia disease is important because there is evidence that the two entities have different etiologies and because several reports indicate that gastric cardia cancer and gastroesphageal junction tumor are increasing in incidence and there is a parallel increased incidence in noncardia cases in the young western populations. ${ }^{[12-14,17]}$

In general, the less developed nations carry a greater gastric cancer disease burden than developed countries. Within all afflicted nations, noncardia gastric cancer is more likely to affect persons of lower socioecomonic groups. ${ }^{[8]}$ Similarly, risk of $H$. pylori infection is associated with lower socioeconomic status, overcrowding and unsanitary conditions. ${ }^{[17]}$ Interestingly, wealth and education have an inverse relationship to noncardia tumors but are associated with cardia gastric cancer ${ }^{[8]}$ In making such observations, it is important to note that other risk factors, including H. pylori infection, tobacco use and diet, may confound the data related to socioeconomic status. ${ }^{[17]}$ The impact of environmental factors is further supported by the fact that first-generation migrants coming from countries of the high incidence to a country of low incidence maintain the risk of the country of origin. The incidence rate decreases in the subsequent generations implicating environmental influences early in life. ${ }^{[18]}$

\section{PATHOLOGIC SUBTYPES AND CHARACTERISTICS}

Several classification systems exist to define gastric cancer but the most frequently used is the Lauren classification. The Lauren classification defines two main histologic subtypes: Intestinal type and diffuse type. ${ }^{[9]}$ Each subtype represents distinct clinical and epidemiologic characteristics. There are rare cases of gastric carcinomas that display features of both histologic subtypes. The morphologic differences between the two subtypes are related to intercellular adhesion molecules, which are preserved in intestinal type disease and defective in diffuse gastric carcinoma. Both subsets can have targetable protein expressions such has human epidermal growth factor receptor 2 (HER2) expression.

Gene amplification is a frequent mode of gene alteration in gastric cancer. Such protein overexpression can be detected by IHC. Amplification of HER2 has been observed in colorectal, lung, gastric and ovarian tumors. ${ }^{[19]}$ In gastric cancer, HER2 overexpression is reported in $7-34 \%$ of tumors, particularly at the G-E junction and in the intestinal type lesions. ${ }^{[20]}$ Epidermal growth factor receptor (EGFR) overexpression has been shown to be a marker for poor prognosis in gastric cancer. ${ }^{[21]}$ Expression of the both vascular endothelial growth 
factor A (VEGFA) and its receptor is reported in about $40 \%$ of gastric cancer cases and increased expression of VEGFA is associated with a poor prognosis and advanced disease. ${ }^{[22]}$ All the above proteins are targets for biologic therapeutic options and have been studied for impact on survival. The details of the therapeutic trials will be discussed later in this review. New biomarkers for targeted therapy are being explored, such as fibroblast growth factor receptor (FGFR), hepatocyte growth factor receptor, and the mammalian target of rapamycin. Some of the new targets are in clinical trials.

\section{INTESTINAL SUBTYPE}

The intestinal subtype is the most frequently diagnosed histology in high-risk populations and is more likely to be sporadic than inherited. ${ }^{[23]}$ It is diagnosed in older individuals, males more than females, and the tumors tend to have the gross appearance of ulcerated masses. ${ }^{[24]}$ Tumor genesis is strongly associated with $H$. pylori infection. As such, the intestinal subtype is linked to the decreasing incidence in gastric cancer seen globally over the last several decades. ${ }^{[24]}$

Chronic infection with $H$. pylori bacterium leads to a sequence of histologic changes that result in a malignant lesion. The cascade of events begins with sustained bacterial infection with $H$. pylori that leads to nonatrophic gastritis that transforms into multifocal atrophic gastritis without metaplasia then into intestinal metaplasia and finally dysplasia develops. ${ }^{[25,26]}$ The prolonged gastric inflammation resulting from chronic H. pylori infection may cause epithelial damage that leads to gastric atrophy characterized by loss of parietal cells and chief cells and glandular atrophy. ${ }^{[2]}$ The gastric epithelium is replaced by intestinal metaplasia, particularly in the lesser curvature of the stomach, but it can be seen anywhere in the stomach. ${ }^{[2]}$ Eventually, foci of dysplasia can develop in the areas of metaplasia. Overtime the areas of dysplasia can invade the lamina propria defining them as invasive carcinoma by western standards. In Japan, severe nuclear and architectural abnormalities in the absence of invasion are considered carcinoma. ${ }^{[27]}$

Several oncogenes are overexpressed in intestinal type tumors; however none have been consistently present in any particular stage of disease. The c-met oncogene is involved with the development of about $20 \%$ of intestinal type gastric cancers and expression of the c-met transcript is associated with more advanced disease. ${ }^{[28]}$ In fact, certain virulent strains of H. pylori form an effector protein that appears to modulate c-met receptor signal transduction pathways, which may lead to tumor initiation and progression. ${ }^{[29]} \mathrm{K}$-ras mutations have also been found in intestinal metaplasia, dysplasia and invasive carcinomas. ${ }^{[30]}$
Alterations in tumor suppressor genes are found in many intestinal type gastric cancers. The P53 tumor suppressor gene (TP53) is an important regulator of the cell cycle. Loss of heterozygosity or mutational inactivation of TP53 expression occurs in more than $60 \%$ of invasive gastric cancers. ${ }^{[31]}$ Abnormalities in TP53 expression have also been observed in H. pylori-associated chronic gastritis, metaplasia and dysplasia; however the relationship between TP53 and H. pylori remains unclear. ${ }^{[32,33]}$ Mutations in the adenomatous polyposis coli gene have also been identified in intestinal and diffuse type gastric tumors and are also linked to H. pylori and gastric tumor initiation and proliferation. ${ }^{[34]}$ Hypermethylation and microsatellites are also observed.

\section{DIFFUSE SUBTYPE}

The diffuse subtype of gastric cancer appears to be more aggressive than the intestinal type. It is generally diagnosed in younger patients and no gender bias exists. ${ }^{[24]}$ While it can be associated with $H$. pylori infection it is more frequently associated with loss of expression of E-cadherin and no precancerous lesions have been defined. ${ }^{[35]}$ Diffuse gastric tumors tend to invade the gastric wall and into adjacent structures, including the duodenum and esophagus without gland formation. Some presentations reveal diffuse infiltration of the gastric wall resulting in linitis plastica. Within this subtype, signet ring cell histology is occasionally observed.

Diffuse gastric tumors have a clear mechanism of carcinogenesis through defective intercellular adhesions. The majority of cases result from loss of expression of the E-cadherin cell adhesion protein. ${ }^{[35]}$ The E-cadherin gene (CDH1) encodes a homodimeric transmembrane cellular adhesion protein that aids in assembling the cell: Cell adhesion complex. ${ }^{[36]}$ The gene appears to function as a tumor suppressor gene requiring a "two hit" model if inactivation. ${ }^{[37]}$ The hereditary form of diffuse gastric cancer (HDGC) has an autosomal dominant pattern of inheritance. The disease presents early in life and has a lifetime cumulative risk of developing gastric cancer of more than $80 \%$ by age $80 .{ }^{[38]}$ Patients with HDGC often present with multifocal tumors under an intact mucosal surface making diagnosis difficult. Patients with CDH1 germline mutations and family history of gastric cancer are referred for prophylactic gastrectomy. ${ }^{[39]}$ Sporadic diffuse gastric carcinomas have also been linked to abnormalities in CDH1. Mutations and loss of heterogygosity in the $\mathrm{CDH} 1$ gene and promoter hypermethylation are observed in sporadic diffuse type gastric tumors. ${ }^{[37,40]}$

\section{Helicobacter pylori}

Gastric cancer is one of the few neoplasms that is directly linked to an infectious organism. H. pylori is a spiral Gram-negative bacterium that colonizes the stomach of 
about half of the world's population and is associated with chronic gastritis, peptic ulcer disease, gastric lymphomas and noncardia adenocarcinomas and is Class I human carcinogen. ${ }^{[15,17,41]} \mathrm{H}$. pylori infection is the strongest known risk factor for the development of gastric cancer, however only a small minority of the infected population develops malignancy. H. pylori infections are more strongly associated with intestinal-type adenocarcinoma than the diffuse subtype of gastric cancer but can be causal in either histology. ${ }^{[42]}$ It is estimated that the infection with the bacterium is responsible for almost $80 \%$ of distal gastric cancer cases, but has little association with cardia gastric carcinoma. ${ }^{[42]}$

The infection is typically acquired during infancy and will remain present for life if left untreated. The inflammation caused by a chronic infection may generate reactive oxygen species which are capable of inducing DNA damage. ${ }^{[1]} H$. pylori is also capable of inducing hypermethylation, particularly of $\mathrm{CpG}$ islands, thereby inactivating tumor suppressor genes. ${ }^{[11]}$ Different strains of the bacteria have variable carcinogenicity. The more aggressive strains carry the cytotoxic-associated gene A (CagA) which encodes an oncogenic protein that can be injected directly into gastric epithelial cells via type IV secretion precipitating a cascade of molecular events linked to carcinogenesis. ${ }^{[43,44]}$ CagA appears to induce disruptions of intracellular junctions, loss of epithelial polarity, increased proliferation, reduced apoptosis leading to carcinogenesis. ${ }^{[45]}$ Most strains in the high-risk areas of East Asia and the Colombian Andes are CagA positive, which helps to explain the increased incidence of the malignancy in these area. ${ }^{[11]}$ The vacA protein is another virulence factor that causes intracellular vacuoles and membrane channels in epithelial cells. ${ }^{[46]}$

Trials of $H$. pylori eradication are logistically difficult since the carcinogenesis from the infection occurs over the course of decades. The current trials have looked at progression and regression of precancerous lesions with eradication of infection. ${ }^{[4]}$ One trial shows a significant reduction in gastric cancer incidence in the group receiving $H$. pylori therapy after 15 years of follow-up. ${ }^{[48]} \mathrm{A}$ separate review of the eradiation trials concluded that there is a point of no return with respect to the development of $H$. pylori associated gastric cancer after which time treatment is ineffective at reducing the risk of malignancy. ${ }^{[49]}$ Until date, the true impact of eradication of the bacteria is unknown.

\section{PARADOXICAL INCREASED INCIDENCE OF GASTRIC CANCER IN A GLOBAL SUBPOPULATION}

Although the overall incidence of gastric cancer is declining both globally and in the United States, a recent observational analysis from the SEER Program reveals increasing rates of noncardia, intestinal type gastric cancer in white US residents ages $25-39$ over the last three decades. ${ }^{[12]}$ The same trend has been observed in Spain and six other European countries. ${ }^{[13,14]}$ The cause of this trend is unclear. The frequent use and possibly abuse, of $\mathrm{H} 2$ blockers and proton pump inhibitor, has been implicated as a precipitating factor but is also unlikely given the young age of the affected population. Another possible hypothesis is the increased frequency of antibiotic use during childhood. ${ }^{[50]}$ The cause of this concerning trend warrants further epidemiologic evaluations in order to prevent further increase in disease burden.

\section{THERAPEUTIC OPTIONS}

Depending on the size and location of the primary tumor, the preferred means of therapy is surgical resection with total or subtotal gastrectomy. Chemotherapeutic interventions have been evaluated in the neoadjuvant, adjuvant, and metastatic settings. The SWOG 9008 trial evaluated postoperative chemoradiation after resection of gastric or G-E junction tumors. Patients were randomized to observation versus 5-FU/leucovorin and radiation up to $45 \mathrm{~Gy}$. The 10 year follow-up revealed significant improvement in OS in the treatment arm; however, postoperative chemotherapy is generally poorly tolerated in this population. ${ }^{[51]}$ The MAGIC trial evaluated perioperative chemotherapy with epirubicin, cisplatin, and 5-FU (ECF) in adenocarcinoma of the G-E junction or lower esophagus and found that the chemotherapy group had significantly higher OS and progression-free survival (PFS) than those who received surgery alone. ${ }^{[52]}$ In the metastatic or recurrent setting any of the combination chemotherapy regimens such as ECF, DCF, FOLFIRI or best supportive care are reasonable options. ${ }^{[53-55]}$

While several targeted therapies have been studied, only two targeted treatments have been approved for use in the United States based on positive clinical trials. Inhibition of HER2 has been tested as a targeted therapy for several cancers. Trastuzumab is a monoclonal antibody that targets HER2 and thereby inhibits HER2 mediated signaling and prevents cleavage of its extracellular domain. ${ }^{[56]}$ A Phase III international study (ToGA trial) evaluated the efficacy of trastuzumab in combination with conventional therapy (cisplatin plus 5-FU or capcitabine). Patients were stratified by HER2 overexpression. Patients treated with trastuzumab and chemotherapy had improved OS compared with chemotherapy alone. ${ }^{[57]}$

Ramucirumab, a monoclonal antibody against vascular endothelial growth factor receptors 2, is the first Food and Drug Administration approved biologic therapy used as a single agent that demonstrates survival benefit in patients 
with advanced gastric cancer or gastroesophageal cancer who have progressed after first-line treatment. ${ }^{[20,58]}$ Although the addition of bevacizumab, a monoclonal antibody against VEGFA, in combination with cisplatin and capecitabine in the treatment of gastric cancer in the AVAGAST trial demonstrated improved overall response rate and PFS, OS was not significantly improved, indicating that bevacizumab does not have a role in the treatment of gastric cancer. ${ }^{[59]}$ Both the EXPAND and REAL3 studies which evaluated the monoclonal antibodies against EGFR, cetuximab and panitumumab, respectively, revealed that the addition of the anti-EGFR antibodies to chemotherapy does not improve survival in advanced gastric cancer. In fact, the addition resulted in inferior OS. ${ }^{[60,61]}$ A clinical trial is underway to evaluate the role of the anti-EGFR antibody, nimotuzumab as an adjunct to irinotecan in the second-line treatment of gastric cancer (Clinicaltrials.gov identifier: NCT01813253). Similar studies are evaluating the benefit of adding biologic agents targeting FGFR (Clinicaltrials.gov identifier: NCT01457846), as well as, the anti-MET antibody, onartuzumab in selected patients (Clinicaltrials.gov identifier: NCT01662869).

\section{FOCUS OF FUTURE ENDEAVORS}

Gastric cancer remains a significant threat to global health. Although there has been a consistent and measureable decline in the incidence of the disease over the last several decades, there is still significant room for improvement with regard to prevention, early detection and intervention and life extending therapies. Clear recommendations for screening and intervention exist in the high-risk populations like those with CDH1 mutations and a family history of gastric cancer. ${ }^{[39]}$ It is less clear whether all high-risk areas should undergo routine screening and treatment of the infectious and carcinogenic organism, H. pylori. No clear recommendations have been made in support of screening for atrophic or dysplastic changes in asymptomatic patients in high-risk regions. It is known that patients found to have atrophic or dysplastic changes in the gastric mucosa are at an increased risk of developing invasive cancer. In this population of patients, endoscopic surveillance is recommended. ${ }^{[62]}$ In Japan, any lesions that are clearly identified are endoscopically resected, which has yielded a 5 -year survival rate up to $90 \%$ in this population. ${ }^{[63]}$ The encouraging results from the Japanese observational analysis serve as a foundation upon which screening guidelines could be established for high-risk patient populations around the world.

\section{REFERENCES}

I. Ferro A, Peleteiro B, Malvezzi M, Bosetti C, Bertuccio P, Levi F, et al. Worldwide trends in gastric cancer mortality (1980-201 I), with predictions to 20I5, and incidence by subtype. Eur J Cancer 2014;50:1330-44.
2. Jemal A, Bray F, Center MM, Ferlay J, Ward E, Forman D. Global cancer statistics. CA Cancer J Clin 201 I;61:69-90.

3. Sasako M, Sakuramoto S, Katai H, Kinoshita T, Furukawa H, Yamaguchi T, et al. Five-year outcomes of a randomized phase III trial comparing adjuvant chemotherapy with $\mathrm{S}-\mathrm{I}$ versus surgery alone in stage II or III gastric cancer. J Clin Oncol 201 I;29:4387-93.

4. Bang Y], Kim YW, Yang HK, Chung HC, Park YK, Lee KH, et al. Adjuvant capecitabine and oxaliplatin for gastric cancer after D2 gastrectomy (CLASSIC): A phase 3 open-label, randomised controlled trial. Lancet 20I2;379:315-2I.

5. Cervantes A, Roda D, Tarazona N, Roselló S, Pérez-Fidalgo JA. Current questions for the treatment of advanced gastric cancer. Cancer Treat Rev 2013;39:60-7.

6. Ferlay J, Shin HR, Bray F, Forman D, Mathers C, Parkin DM. Estimates of worldwide burden of cancer in 2008: GLOBOCAN 2008. Int J Cancer 2010;127:2893-917.

7. Ferlay J, Steliarova-Foucher E, Lortet-Tieulent J, Rosso S, Coebergh JW, Comber $\mathrm{H}$, et al. Cancer incidence and mortality patterns in Europe: Estimates for 40 countries in 2012. Eur J Cancer 2013;49:1374-403.

8. Power C, Hyppönen E, Smith GD. Socioeconomic position in childhood and early adult life and risk of mortality: A prospective study of the mothers of the 1958 British birth cohort. Am J Public Health 2005;95:1396-402.

9. Lauren P. The two histological main types of gastric carcinoma: Diffuse and so-called intestinal-type carcinoma. An attempt at a histo-clinical classification. Acta Pathol Microbiol Scand 1965;64:31-49.

10. La Vecchia C, Negri E, D'Avanzo B, Franceschi S. Electric refrigerator use and gastric cancer risk. Br J Cancer 1990;62:136-7.

II. Correa P. Gastric cancer: Overview. Gastroenterol Clin North Am 2013;42:2II-7.

12. Anderson WF, Camargo MC, Fraumeni JF Jr, Correa P, Rosenberg PS, Rabkin CS. Age-specific trends in incidence of noncardia gastric cancer in US adults. JAMA 2010;303:1723-8.

13. Sonnenberg A. Time trends of mortality from gastric cancer in Europe. Dig Dis Sci 20I I;56: I I I2-8.

14. Aragonés N, Pollán M, López-Abente G, Ruiz M,Vergara A, Moreno C, et al. Time trend and age-period-cohort effects on gastric cancer incidence in Zaragoza and Navarre, Spain.J Epidemiol Community Health 1997;5 I:4 I2-7.

15. Schistosomes, liver flukes and Helicobacter pylori. IARC Working Group on the Evaluation of Carcinogenic Risks to Humans. Lyon, 7-I4 June 1994. IARC Monogr Eval Carcinog Risks Hum 1994;6I:I-24I.

16. Ferlay J, Parkin DM, Steliarova-Foucher E. Estimates of cancer incidence and mortality in Europe in 2008. Eur J Cancer 2010;46:765-8I.

17. de Martel C, Forman D, Plummer M. Gastric cancer: Epidemiology and risk factors. Gastroenterol Clin North Am 2013;42:2 19-40.

18. HaenszelW. Report of the working group on studies of cancer and related diseases in migrant populations. Int J Cancer 1969;4:364-7I.

19. Gravalos C, jimeno A. HER2 in gastric cancer: A new prognostic factor and a novel therapeutic target.Ann Oncol 2008;19:1523-9.

20. Durães C, Almeida GM, Seruca R, Oliveira C, Carneiro F. Biomarkers for gastric cancer: Prognostic, predictive or targets of therapy? Virchows Arch 20I4;464:367-78.

21. Graziano F, Galluccio N, Lorenzini P, Ruzzo A, Canestrari E, D’Emidio S, et al. Genetic activation of the MET pathway and prognosis of patients with high-risk, radically resected gastric cancer.J Clin Oncol 201 I;29:4789-95.

22. Yoshikawa T,Tsuburaya A, Kobayashi O, Sairenji M, Motohashi H, Yanoma S, et al. Plasma concentrations of VEGF and bFGF in patients with gastric carcinoma. Cancer Lett 2000;153:7-12.

23. Henson DE, Dittus C, Younes M, Nguyen H,Albores-Saavedra J. Differential trends in the intestinal and diffuse types of gastric carcinoma in the United States, 1973-2000: Increase in the signet ring cell type.Arch Pathol Lab Med 2004; 128:765-70.

24. Piazuelo MB, Correa P. Gastric cáncer: Overview. Colomb Med (Cali). 2013;44:192-20I. eCollection 2013.

25. Correa P, Haenszel W, Cuello C, Tannenbaum S, Archer M. A model for gastric cancer epidemiology. Lancet 1975;2:58-60.

26. Correa P, Piazuelo MB.The gastric precancerous cascade.J Dig Dis 2012;13:2-9.

27. Rugge M, Correa P, Dixon MF, Hattori T, Leandro G, Lewin K, et al. Gastric dysplasia:The Padova international classification. Am J Surg Pathol 2000;24:167-76. 
28. Smith MG, Hold GL, Tahara E, El-Omar EM. Cellular and molecular aspects of gastric cancer.World J Gastroenterol 2006; I 2:2979-90.

29. Churin Y, Al-Ghoul L, Kepp O, Meyer TF, Birchmeier W, Naumann M. Helicobacter pylori CagA protein targets the c-Met receptor and enhances the motogenic response.J Cell Biol 2003;161:249-55.

30. Yasui W, Oue N, Kuniyasu H, Ito R, Tahara E, Yokozaki H. Molecular diagnosis of gastric cancer: Present and future. Gastric Cancer 2001;4:I| 3-2I.

31. Yasui W, Sentani K, Motoshita J, Nakayama H. Molecular pathobiology of gastric cancer. Scand J Surg 2006;95:225-3I.

32. Morgan C, Jenkins GJ, Ashton T, Griffiths AP, Baxter JN, Parry EM, et al. Detection of p53 mutations in precancerous gastric tissue. $\mathrm{Br} J$ Cancer 2003;89:1314-9.

33. Li JH, Shi XZ, Lv S, Liu M, Xu GW. Effect of Helicobacter pylori infection on p53 expression of gastric mucosa and adenocarcinoma with microsatellite instability. World J Gastroenterol 2005; I :4363-6.

34. Nakatsuru S, Yanagisawa A, Furukawa Y, Ichii S, Kato Y, Nakamura Y, et al. Somatic mutations of the APC gene in precancerous lesion of the stomach. Hum Mol Genet 1993;2:1463-5.

35. Barber M, Murrell A, Ito Y, Maia AT, Hyland S, Oliveira C, et al. Mechanisms and sequelae of E-cadherin silencing in hereditary diffuse gastric cancer. J Pathol 2008;21 6:295-306

36. Graziano F, Humar B, Guilford P.The role of the E-cadherin gene (CDHI) in diffuse gastric cancer susceptibility: From the laboratory to clinical practice. Ann Oncol 2003; I4:1705-13.

37. Grady WM, Willis J, Guilford PJ, Dunbier AK, Toro TT, Lynch H, et al. Methylation of the $\mathrm{CDHI}$ promoter as the second genetic hit in hereditary diffuse gastric cancer. Nat Genet 2000;26:16-7.

38. Fitzgerald RC, Hardwick R, Huntsman D, Carneiro F, Guilford P, Blair V, et al. Hereditary diffuse gastric cancer: Updated consensus guidelines for clinical management and directions for future research.J Med Genet 2010;47:436-44.

39. Charlton A, Blair V, Shaw D, Parry S, Guilford P, Martin IG. Hereditary diffuse gastric cancer: Predominance of multiple foci of signet ring cell carcinoma in distal stomach and transitional zone. Gut 2004;53:8I4-20.

40. Humar B, Graziano F, Cascinu S, Catalano V, Ruzzo AM, Magnani M, et al. Association of $\mathrm{CDHI}$ haplotypes with susceptibility to sporadic diffuse gastric cancer. Oncogene 2002;21:8192-5.

4I. Plummer M, Franceschi S,Vignat J, Forman D, de Martel C. Global burden of gastric cancer attributable to pylori. Int J Cancer 2014.

42. Helicobacter and Cancer Collaborative Group. Gastric cancer and Helicobacter pylori: A combined analysis of 12 case control studies nested within prospective cohorts. Gut 200 I;49:347-53.

43. Censini S, Lange C, Xiang Z, Crabtree JE, Ghiara P, Borodovsky M, et al. Cag, a pathogenicity island of Helicobacter pylori, encodes type I-specific and disease-associated virulence factors. Proc Natl Acad Sci U S A 1996;93:I4648-53.

44. Covacci A, Censini S, Bugnoli M, Petracca R, Burroni D, Macchia G, et al. Molecular characterization of the I28-kDa immunodominant antigen of Helicobacter pylori associated with cytotoxicity and duodenal ulcer. Proc Natl Acad Sci U S A 1993;90:579I-5.

45. Hatakeyama M. Helicobacter pylori and gastric carcinogenesis.J Gastroenterol 2009;44:239-48.

46. Cover TL, Blanke SR. Helicobacter pylori VacA, a paradigm for toxin multifunctionality. Nat Rev Microbiol 2005;3:320-32.

47. IARCWorking Group on the Evaluation of Carcinogenic Risks to Humans. Biological agents. Volume 100 B. A review of human carcinogens. IARC Monogr Eval Carcinog Risks Hum 20 12; 100: I-44I.

48. Ma JL, Zhang L, Brown LM, Li JY, Shen L, Pan KF, et al. Fifteen-year effects of Helicobacter pylori, garlic, and vitamin treatments on gastric cancer incidence and mortality.J Natl Cancer Inst 2012;104:488-92.
49. Roesler BM, Costa SC, Zeitune JM. Eradication treatment of Helicobacter pylori infection: Its importance and possible relationship in preventing the development of gastric cancer. ISRN Gastroenterol 2012;2012:9354I0.

50. Correa P. Gastric cancer:Two epidemics? Dig Dis Sci 20I I;56:1585-6.

51. Macdonald JS, Smalley SR, Benedetti J, Hundahl SA, Estes NC, Stemmermann GN, et al. Chemoradiotherapy after surgery compared with surgery alone for adenocarcinoma of the stomach or gastroesophageal junction. N Engl J Med 200I;345:725-30.

52. Cunningham D, Allum WH, Stenning SP, Thompson JN, Van de Velde CJ, Nicolson M, et al. Perioperative chemotherapy versus surgery alone for resectable gastroesophageal cancer. N Engl J Med 2006;355: I I-20.

53. Cunningham D, Starling N, Rao S, Iveson T, Nicolson M, Coxon F, et al. Capecitabine and oxaliplatin for advanced esophagogastric cancer. N Engl J Med 2008;358:36-46.

54. Van Cutsem E, Moiseyenko VM, Tjulandin S, Majlis A, Constenla M, Boni C, et al. Phase III study of docetaxel and cisplatin plus fluorouracil compared with cisplatin and fluorouracil as first-line therapy for advanced gastric cancer:A report of the V325 Study Group.J Clin Oncol 2006;24:499I-7.

55. Dikken JL, van Sandick JW, Maurits Swellengrebel HA, Lind PA, Putter H, Jansen EP, et al. Neo-adjuvant chemotherapy followed by surgery and chemotherapy or by surgery and chemoradiotherapy for patients with resectable gastric cancer (CRITICS). BMC Cancer 201 I; I I:329.

56. Hudis CA. Trastuzumab- mechanism of action and use in clinical practice. N Engl J Med 2007;357:39-5I.

57. Bang YJ, Van Cutsem E, Feyereislova A, Chung HC, Shen L, Sawaki A, et al. Trastuzumab in combination with chemotherapy versus chemotherapy alone for treatment of HER2-positive advanced gastric or gastro-oesophageal junction cancer (ToGA): A phase 3, open-label, randomised controlled trial. Lancet 20I0;376:687-97.

58. Fuchs CS, Tomasek J, Yong CJ, Dumitru F, Passalacqua R, Goswami C, et al. Ramucirumab monotherapy for previously treated advanced gastric or gastro-oesophageal junction adenocarcinoma (REGARD): An international, randomised, multicentre, placebo-controlled, phase 3 trial. Lancet 20I4;383:3I-9.

59. Ohtsu A, Shah MA, Van Cutsem E, Rha SY, Sawaki A, Park SR, et al. Bevacizumab in combination with chemotherapy as first-line therapy in advanced gastric cancer: A randomized, double-blind, placebo-controlled phase III study.J Clin Oncol 20I I;29:3968-76.

60. Lordick F, Kang YK, Chung HC, Salman P, Oh SC, Bodoky G, et al. Capecitabine and cisplatin with or without cetuximab for patients with previously untreated advanced gastric cancer (EXPAND): A randomised, open-label phase 3 trial. Lancet Oncol 2013; 14:490-9.

6I. Okines AF, Ashley SE, Cunningham D, Oates J, Turner A, Webb J, et al. Epirubicin, oxaliplatin, and capecitabine with or without panitumumab for advanced esophagogastric cancer: Dose-finding study for the prospective multicenter, randomized, phase II/III REAL-3 trial. J Clin Oncol 2010;28:3945-50.

62. Correa P, Piazuelo MB, Wilson KT. Pathology of gastric intestinal metaplasia: Clinical implications. Am J Gastroenterol 2010;105:493-8.

63. Miyahara R, Niwa Y,Matsuura T, Maeda O,AndoT, Ohmiya N, et al. Prevalence and prognosis of gastric cancer detected by screening in a large Japanese population: Data from a single institute over 30 years. J Gastroenterol Hepatol 2007;22: 1435-42.

How to cite this article: Carcas LP. Gastric cancer review. J Carcinog 2014;13:14.

Source and Support: Nil. Conflict of Interest: None declared. 


\section{AUTHOR'S PROFILE}

Lauren Peirce Carcas: Florida Cancer Care, Plantation and Boca Raton, Florida, Remains active in Research and Clinical trials.

Dournal of Carcinogenesis is published for 2. Carcinogenesis Press by Medknow Publications and Media Pvt. Ltd.

Manuscripts submitted to the journal are peer reviewed and published immediately upon acceptance, cited in PubMed and archived on PubMed Central. Your research papers will be available free of charge to the entire biomedical community. Submit your next manuscript to Journal of Carcinogenesis.

www.journalonweb.com/jcar/ 